\title{
El desarrollo del radar de navegación marítima en los primeros años del franquismo
}

\section{The development of the sea navigation radar at the beginning of Francoism}

\author{
FRANCISCO SÁEZ DE ADANA \\ Instituto Franklin, Universidad de Alcalá de Henares \\ kiko.saez@uah.es
}

Resumen: En este artículo se estudia el desarrollo de la tecnología radar en España durante los primeros años del franquismo. Se estudian las especificaciones técnicas de los prototipos desarrollados por el equipo del Instituto Nacional de Electrónica (INE) del que formaban parte un grupo de ingenieros alemanes que habían trabajado en el radar alemán durante la II Guerra Mundial. Se muestra en este artículo la problemática y la motivación que llevó al INE a trabajar en estos prototipos y se contextualizan los mismos con respecto al estado de la tecnología de la época.

Palabras clave: Historia del radar, equipo de comunicaciones, tecnología y otros servicios, innovación e invención, franquismo.

Abstract: This paper shows the development of the radar technology in Spain during the first years of Francoism. It is studied the technical specifications of the prototypes developed by the Electronic National Institute (Instituto Nacional de Electrónica, INE). One of its teams consists of a group of German engineers who had worked in the German radar during World War II. The problematic and motivation which drive the INE to work in these prototypes are shown, and they are contextualized with respect to the state of the technology at that time.

Keywords: Radar history, Communications Equipment, Technology and Other Services, Innovation and Invention, Francoism.

Recibido: 1 de noviembre de 2017; aceptado: 12 de marzo de 2018; publicado: 27 de septiembre de 2018. Revista Historia Autónoma, 13 (2018), pp. 181-205

DOI: https://doi.org/10.15366/rha2018.13.010 
Introducción ${ }^{1}$

El radar recibe su nombre de la contracción del término inglés Radio Detection And Ranging. La Unión Internacional de Telecomunicaciones (UIT) define el radar como: "Sistema de Radiodeterminación basado en la comparación entre señales radioeléctricas reflejadas o retransmitidas desde la posición a determinar"2, definición que es ampliada en el estándar por el Institute of Electrical and Electronics Engineers de la siguiente manera: "un dispositivo para la transmisión de señales electromagnéticas y la recepción de ecos desde los objetos de interés (blancos) dentro de su volumen de cobertura. La presencia del blanco es revelada por la detección de su eco"3. Por tanto, el radar consta de una antena transmisora, emitiendo una radiación electromagnética generada por un transmisor que, al ser interceptada por un objeto reflectante (blanco) es reradiada en todas las direcciones, de manera que la energía reradiada en la dirección del radar se denomina eco. La antena receptora del radar recoge esa energía reflejada y la aplica al receptor, donde es procesada para detectar la presencia del blanco y extraer algunos datos del mismo como su posición y su velocidad relativa.

El radar fue uno de los adelantos técnicos decisivos en la II Guerra Mundial. A pesar de que Gran Bretaña, Alemania, Rusia y Francia realizaron experimentos utilizando el radar, fue solamente en Gran Bretaña donde el desarrollo de esta tecnología se ligó desde el comienzo a un sistema de defensa aéreo extensivo. La apuesta por el desarrollo del radar por parte de Gran Bretaña, a la que luego se uniría Estados Unidos, resultó decisiva para el curso de la guerra. Pese a la importancia que adquirió el radar en la II Guerra Mundial y su posterior desarrollo tecnológico, este papel ha sido a menudo ignorado en los estudios generales sobre la historia de la tecnología

Frente al protagonismo que han tenido los estudios sobre el Proyecto Manhattan, las investigaciones sobre el radar y su papel en la II Guerra Mundial empiezan a tener espacio en la historiografía. Como afirma Davis Munns, en los últimos años diferentes publicaciones han señalado al radar como el "verdadero héroe científico" de la II Guerra Mundial, por encima de la bomba atómica: tras el lanzamiento de las bombas de Hiroshima y Nagasaki, los científicos relacionados con el radar bromeaban afirmando que la bomba había acabado con la guerra, pero el radar la había ganado5. La desgraciada espectacularidad de la bomba atómica, ha desviado la atención de los historiadores hacia el Proyecto Manhattan como ejemplo fundamental de la aplicación de la ciencia y la tecnología con fines militares. Sin embargo, según las memorias de

\footnotetext{
${ }^{1}$ Este proyecto ha sido financiado, en parte, por el Instituto Franklin de la Universidad de Alcalá, proyecto IF2014001 y por el Ministerio de Economía y Competitividad, proyectos HAR2014-57776-P y HAR2014-58685-R.

${ }^{2}$ Normativa Radio de la UIT.

${ }^{3}$ Estándar IEEE Std 686-1990.

${ }^{4}$ Blumtritt, Oskar, "Introduction", en Blumtritt, Oskar (coord.), Tracking the history of radar. Piscataway, Center for the History of Electrical Engineering, 1994, p. VIII.

${ }^{5}$ Munns, Davis, "Magnetrons, micropups and me: personal histories of radar", en Metascience, 10 (2010), p. 407.
} 
Luis Álvarez ${ }^{6}$, podemos encontrar paralelismos entre la historia del entorno científico en Los Álamos y en el Radiation Laboratory del MIT? . Por otro lado, las investigaciones de Walter Kaiser sobre este laboratorio indican que su presupuesto supuso alrededor del $25 \%$ del Office of Scientific Research and Development (OSRD). Si a esto añadimos que el Ejército y la Marina gastaron 1500 millones de dólares en el equipamiento del radar del Radiation Laboratory, las cantidades se aproximarían bastante a los 2000 millones de dólares del Proyecto Manhattan ${ }^{8}$. Otras publicaciones han destacado el papel del radar en la Batalla de Inglaterra y en la protección aérea del territorio aliado durante la II Guerra Mundial`.

Otro problema del que se han ocupado investigadores como Hartmut Petzold es que el desarrollo del radar durante la II Guerra Mundial ha focalizado prácticamente todos los estudios sobre el tema. Y por el contrario existe poca bibliografía sobre el desarrollo del radar en los años posteriores a la guerra ${ }^{10}$. Hay que tener en cuenta que ya en los años 40 , después de su desarrollo para uso militar, el radar se empezó a utilizar para aplicaciones civiles, principalmente como ayuda a las navegaciones aérea y marítima. Sin embargo, el hecho de que el radar, al contrario que otros sistemas de telecomunicación, no se haya producido para ser vendido en masa, hace que esta tecnología se haya ligado más a instituciones y burocracias nacionales, internacionales, civiles y militares que otros sistemas ${ }^{11}$. Por otro lado, fuera del ámbito anglosajón, con la incorporación reciente, en menor medida, del caso alemán, la historia del radar no ha sido estudiada en el marco de los diferentes ámbitos nacionales, a excepción de algunas contribuciones dentro del panorama italiano ${ }^{12}$.

Este trabajo, por tanto, constituye una aportación a la historia del radar en un marco diferente de los tradicionales y, más concretamente, en el ámbito español. El hecho de que el desarrollo del radar en otros países, como es el caso de España, se realizara en los años posteriores a la II Guerra Mundial y que no tuviera incidencia en el conflicto, ha tenido como resultado la escasa existencia de estudios dedicados al desarrollo de esta tecnología en otras realidades nacionales. Este artículo está dedicado, por tanto, al caso español y se centra en el primer franquismo. A este respecto se han encontrado referencias en trabajos sobre historia

\footnotetext{
${ }^{6}$ Luis Álvarez fue responsable en el MIT de tres sistemas radar durante la II Guerra Mundial, dedicados tanto a la detección de blancos, como a la ayuda para el bombardeo de gran altitud.

${ }^{7}$ Munns, Davis, "Magnetrons, micropups..." op. cit., p. 408.

${ }^{8}$ Kaiser, Walter, "The development of electron tubes and of radar technology", en Blumtritt, Oskar (coord.), Tracking the history... op. cit., p. 229.

${ }^{9}$ Brown, Louis, A radar history of World War Two: Technical and military imperatives, Bristol, Institute of Physics Publishing, 1999; Edgerton, David, The Shock of the Old: Technology and Global History since 1900, Oxford, Oxford University Press, 2011; Watson-Watt, Robert, Three steps to victory. A personal account for radar's greatest pioneers, Michigan, Odhams Press, 1957.

${ }^{10}$ Petzold, Hartmut, "Some problems of radar systems historiography", en Blumtritt, Oskar (coord.), Tracking the history... op. cit., p. 247.

${ }^{11}$ Ibídem, p. 253.

${ }^{12}$ Carillo Castioni, Luigi, "I radar industriali italiani: Ricerche, ricordi, considerazioni per una loro storia", en Storia Contemporanea, 18 (1987), pp. 1221-1265; Ottanelli, Andrea. "Il radar italiano", en Coltello di Delfo, 8 (1988), pp. 5-11.
} 
económica del primer franquismo ${ }^{13}$. A comienzos de los cincuenta, el Patronato Juan de la Cierva acogió en el Instituto Nacional de Electrónica (INE) a seis investigadores alemanes, Fritz Kallies, Erich Keller, Adolf-Echard Hoffman-Heyden, Richard Schaefer, Joseph Diels y W. Rupper, que habían trabajado en radares en Alemania durante la II Guerra Mundial. Aunque algunos de ellos no concluyeron su trabajo al regresar en un espacio menor de dos años a su país natal, los que se quedaron pidieron al Patronato que facilitase la incorporación de algunos de sus ayudantes y colaboradores, como fue el caso de Hans-Karl Fuchs, Fritz Wätcher y Fritz Schöfer. El INE se convirtió en un centro de primer orden mundial en los temas de radares y radiofrecuencia, especialmente en lo que se refiere al radar de navegación marítima. Este será uno de los aspectos fundamentales que se tratarán en este artículo.

Con el fin de acotar el objeto de estudio, este artículo se centra en los primeros prototipos de radar realizados en España. Estos prototipos del INE fueron diseñados para la ayuda a la navegación marítima tanto civil como militar, aunque posteriormente se aplicó también a la navegación aérea como se mostrará brevemente en este artículo. El esfuerzo del INE en el desarrollo de la tecnología radar hizo de ella una de los pocas tecnologías en las que se logró un acercamiento al nivel de otros países. Este desarrollo no ha sido estudiado hasta la fecha. Se trata, por tanto, de recuperar las aportaciones tecnológicas realizadas por el INE en materia de radar, mostrando las aplicaciones para las que se utilizaron. Hay que tener en cuenta, y esta es otra de las hipótesis de partida de este trabajo, que el radar fue fundamental para el avance de la física ${ }^{14}$ y para configurar el diseño de sistemas de ingeniería tal y como lo conocemos actualmente ${ }^{15}$. En este caso, se trata también de mostrar ese papel en el caso español.

El trabajo se enmarca en el ámbito de la historiografía sobre la ciencia y la tecnología en España, al que tantas aportaciones se han realizado en los últimos años. Así se puede citar el trabajo de Ana Romero de Pablos y José Manuel Sánchez Ron sobre la introducción de la energía nuclear en España ${ }^{16}$, el de María Jesús Santesmases sobre la investigación farmacéutica en los primeros años del franquismo ${ }^{17}$ o el libro editado por Xavier Roqué y Néstor Herrán sobre la física en la dictadura franquista ${ }^{18}$. Más relacionados con este trabajo están la historia de diferentes organismos que fueron fundamentales para el desarrollo de la tecnología en la España franquista, como la historia del Instituto Nacional de Técnica Aeroespacial realizada

\footnotetext{
${ }_{13}^{13}$ López García, Santiago, El saber tecnológico en la política industrial del primer franquismo, tesis doctoral, Universidad Complutense de Madrid, 1994.

${ }^{14}$ Forman, Paul, "Swords Into Ploughshares: Breaking New Ground with Radar Hardware and Technique in Physical Research After World War II", en Reviews of Modern Physics, 67 (1995), pp. 397-455.

${ }^{15}$ Mindel, David, “Automation's Finest Hour: Radar and System Integration in World War II”, en Hughes, Agatha C. y Thomas P. Hughes, Systems, Experts and Computers. The Systems Approach in Management and Engineering, Cambridge, MIT Press, 2000, pp. 27-56.

${ }^{16}$ Romero, Ana y José Manuel Sánchez Ron, De la JEN al Ciemat: Energía nuclear en España, Madrid, Centro de Investigaciones Energéticas, Medioambientales y Tecnológicas, 2001.

${ }^{17}$ Santesmases, María José, Antibióticos en la autarquía: Banca privada, industria farmacéutica, investigación cientifica y cultura liberal en España, 1940-1960, Madrid, Fundación Empresa Pública, 1999.

${ }^{18}$ Herrán, Néstor y Xavier Roqué (coords.), La física en la dictadura. Físicos, cultura y poder en España 19391975, Barcelona, Universidad Autónoma de Barcelona, 2012.
} 
por José Manuel Sánchez Ron ${ }^{19}$, la del nacimiento del INI escrita por Elena San Román ${ }^{20}$, los trabajos de José Manuel Sánchez Ron ${ }^{21}$ o María José Santesmases y Emilio Múñoz ${ }^{22}$ sobre los inicios del Consejo Superior de Investigaciones Científicas, además de la tesis ya mencionada de Santiago López García, donde se recoge la historia del Patronato Juan de la Cierva y del $\mathrm{INE}^{23}$, o el libro editado por Miguel Ángel Puig-Samper Mulero sobre la historia del CSIC ${ }^{24}$. Teniendo en cuenta, por otro lado, que el diseño y fabricación de equipos radar es una labor de ingeniería, es fundamental citar de nuevo el reciente libro de Lino Camprubí ${ }^{25}$ sobre el papel de los ingenieros civiles en el régimen franquista, que recoge muchos aspectos de estandarización y modelos de producción aplicables al caso del radar.

La estructura del artículo es como sigue: tras esta introducción, se justificará la necesidad de los radares de navegación marítima en el caso español, y los problemas principalmente de capital humano que la introducción de esta tecnología suponía en los puertos españoles, con el fin de justificar la aproximación que el INE llevó a cabo a la hora de plantearse la realización de sus prototipos. Posteriormente, se describirán brevemente las especificaciones técnicas de dichos prototipos, indicando su relación con la tecnología de la época. Se mostrarán también las pruebas realizadas antes de la puesta en marcha de los prototipos. Finalmente, antes de llegar a las conclusiones, se mostrará la aplicación de la tecnología desarrollada a la navegación aérea.

\section{El radar y la navegación marítima}

El desarrollo de un prototipo de radar para la navegación marítima en España vino motivado, fundamentalmente, para evitar los retrasos y las esperas de los buques en condiciones climatológicas adversas, ya que estos tenían que esperar la intervención de un práctico para entrar en puerto, de tal forma que si este no era capaz de percibir el barco hasta que se encontrara en las cercanías del puerto, era necesaria una parada más o menos prolongada antes de la entrada en puerto, con el consiguiente retraso. Manuel Espinosa, director del $\mathrm{INE}^{26}$, consciente de la

\footnotetext{
${ }^{19}$ Sánchez Ron, José Manuel, INTA. 50 años de ciencia y técnica aeroespacial, Madrid, Ministerio de Defensa, Doce Calles, Instituto Nacional de Técnica Aeroespacial, 1997.

${ }^{20}$ San Román, Elena, Ejército e industria: el nacimiento del INI, Barcelona, Crítica, 1999.

${ }^{21}$ Sánchez Ron, José Manuel, "Política científica e ideología: Albareda y los primeros años del Consejo Superior de Investigaciones Científicas", en Boletín de la Institución Libre de Enseñanza, 14 (1992), pp. 53-74.

${ }^{22}$ Santesmases, María José y Emilio Munoz, "Las primeras décadas del Consejo Superior de Investigaciones Científicas: una introducción a la política científica del régimen franquista", en Boletín de la Institución Libre de Enseñanza, 16 (1993), pp. 73-94.

${ }^{23}$ López García, Santiago, El saber tecnológico... op. cit.

${ }^{24}$ Puig-Samper, Miguel Ángel (coord.), Tiempos de investigación: JAE-CSIC, cien años de ciencia en España, Madrid, Consejo Superior de Investigaciones Científicas, 2007.

${ }^{25}$ Camprubí, Lino, Engineers and the making of the Francoist regime, Boston, MIT Press, 2014.

${ }^{26}$ El INE fue fundado en 1948 bajo la dirección de Esteban Terradas. A principios de 1949 Terradas fue sustituido por Manuel Espinosa en la dirección del mismo. Para más información sobre la formación del INE, ver López García, Santiago, El saber tecnológico... op. cit.
} 
presencia de equipos de este tipo en las más conocidas instalaciones portuarias extranjeras, como los casos explícitamente mencionados de Londres y Hamburgo, consideró necesaria la instalación de equipos de este tipo en los puertos españoles ${ }^{27}$. Espinosa, desde finales de los años 40, había incluido la tecnología radar como una de las prioridades del INE manteniendo contactos con empresas e instituciones tanto británicas como francesas, incluyendo una visita a las instalaciones del Institute Aeronautique de París, en el año 1949, para observar los avances que en esta tecnología se estaban realizando en Francia. Hay que tener en cuenta que, con posterioridad a la II Guerra Mundial, países como España y Alemania quedaron fuera de la investigación en radar, teniendo que desarrollar sus propios prototipos, siendo más problemático el caso alemán, donde, hasta 1950, tuvieron prohibida la investigación y la fabricación de equipos radar, pudiendo a partir de ese año fabricar radares para aplicaciones civiles, con la condición de que las licencias de los mismos procedieran de fuera de Alemania ${ }^{28}$. En estas circunstancias, la idea de un prototipo más sencillo prevalecía a la hora de afrontar esta realización. Tanto en Hamburgo como en Londres se disponía de varios equipos radar, de tal manera que cada uno de ellos cubría una parte de la zona del puerto o de su entrada, para posteriormente transmitir las imágenes de cada uno de estos equipos a un puesto central, donde se conocía, por tanto, la situación en todo el área y se tomaban las medidas oportunas. La multiplicidad de equipos venía sobre todo dada por tratarse de zonas portuarias muy extensas, situadas en la desembocadura de los ríos y, por tanto, a muchos kilómetros de mar abierto. Sin embargo, en los puertos españoles de mayor importancia no existía esta dificultad, por lo que, a principios de los años 50, se optó por un equipo de una sola pantalla convenientemente situado que daba cobertura a toda el área. La idea era mantener los criterios de sencillez, economía y bajo volumen y peso. Con este objetivo, se recogieron todos los adelantos de la técnica radar conocidos (lo cual, dado el secretismo de algunos países, no implicaba que se estuviera al tanto del estado de la cuestión), así como algunas novedades procedentes de patentes del Instituto como por ejemplo el sistema generador de radiación patentado en octubre de 1950 o el transformador-amplificador de banda ancha patentado en diciembre de $1951^{29}$.

Con esta idea, a finales de 1952 se comenzó la ejecución de un prototipo de radar, inicialmente dedicado a la navegación marítima pero que con pocas alteraciones pudiera servir también para la navegación aérea y la defensa. Se empezó a trabajar en los radares instalados en puerto para, inmediatamente después, extender el trabajo a los radares instalados en los barcos. Este trabajo se realizó en colaboración estrecha con algunos departamentos militares que financiaban algunas de las tareas del Instituto, incluyendo el desarrollo del radar. El interés de disponer de equipos radar por parte del estamento militar se debía fundamentalmente a su deseo

\footnotetext{
$\overline{27}$ Jiménez Asenjo, Felipe y Erich Meyer-Doneher, "Realizaciones del INE: Radar para vigilancia de puertos", en Revista del INE, 2 (1959), pp. 305-317.

${ }^{28}$ Holpp, Wolfgang, "The century of radar: from Christian Hülsmeyer to shuttle Radar Topography Mission", en Ortung und Navigation, 2 (2002), pp. 7-31.

${ }^{29}$ Patentes ES0194069 A1 del 10 de octubre de 1950 y ES0200530 A1 del 16 de diciembre de 1951, respectivamente.
} 
de aplicar dicha tecnología para la vigilancia en lugares estratégicos como Gibraltar $^{30}$ y para la ayuda en la predicción meteorológica, militarizada durante el franquismo ${ }^{31}$. Para entender las motivaciones básicas que configuraron la aproximación del INE a la hora de afrontar su diseño de un radar de navegación marítima es interesante realizar un pequeño salto cronológico hasta mediados de 1954 en el Congreso Internacional de Radiolocalización celebrado en Bremen, donde se presentó el prototipo desarrollado. En este congreso, Manuel Espinosa Rodríguez, Director y Consejero-Delegado del INE, pronunció una conferencia sobre los problemas del radar de navegación ${ }^{32}$. La idea de esta conferencia, como el propio autor afirmó en su momento, no era ofrecer soluciones ni pedir ciertas especificaciones técnicas a los fabricantes de equipos radar, sino presentar ciertos problemas que, desde la experiencia española, presentaba el radar de navegación marítima y que se ofrecían "a quienes, más preparados técnica e industrialmente que nosotros, estén en excelentes condiciones para resolverlos de manera brillante" ${ }^{33}$. Por tanto, pese al éxito de los equipos presentados, se reconocía la inferioridad tanto técnica como industrial de nuestro país con respecto a otros países participantes en el Congreso.

La conferencia de Espinosa se dividió en cuatro partes: material actual de radar de a bordo, problemas de personal, problemas de empleo y futuro. En la primera parte, Espinosa presenta los problemas técnicos de los radares de la época. En primer lugar, presenta las deficiencias de las bandas X y S, bandas mayoritariamente usadas en los equipos de la época, planteándose la posibilidad de la realización de un equipo que trabaje en ambas bandas, ya que la banda $\mathrm{X}$ permitía detectar embarcaciones en condiciones de borrasca que no se podían detectar a frecuencias menores, mientras que en la banda $\mathrm{S}$ disminuía la probabilidad de que una masa de precipitaciones ocultara el objetivo ${ }^{34}$. También se planteó la gran cantidad de perturbaciones del servicio, haciendo referencia a un artículo de un oficial de la Marina de Estados Unidos, donde se afirmaba que el $10 \%$ de sus aparatos electrónicos estaba siempre fuera de servicio, mientras que otro $50 \%$ no funcionaba con seguridad. Esto suponía un $60 \%$ de equipos que necesitaban inspección y reparaciones, lo que creaba un gran problema de seguridad, especialmente en la navegación civil, donde los tripulantes de los barcos no tenían los conocimientos necesarios para llevar a cabo dichas reparaciones. La mayor fuente de problemas, según Espinosa, eran los tubos electrónicos, por lo que había que realizar un fuerte esfuerzo en la sencillez de construcción del radar, aspecto en el que el Instituto ponía especial hincapié con su diseño modular e invertir fuertemente en mantener los tubos en su estado óptimo de funcionamiento,

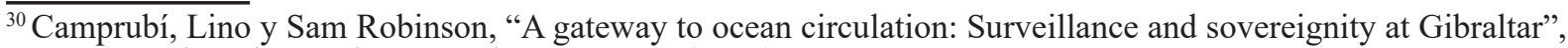
en Historical Studies in the Natural Sciences, 46 (2016), pp. 429-459.

${ }^{31}$ Anduaga, Aitor, "Towards a new space of practices and knowledge: The militarization of meteorology of Francoist Spain”, en Science in Context, 26 (2013), pp. 31-59.

${ }^{32}$ En alemán, tal y como recogen los documentos de la época.

${ }^{33}$ Espinosa Rodríguez, Manuel, “Algunos problemas sobre radar de navegación”, en Revista de ciencia aplicada, 8 (1954), pp. 289-298.

${ }^{34}$ Radares operando en ambas frecuencias no se han desarrollado hasta finales de la década de 1990.
} 
aspecto que conllevaba un coste económico que cada tripulación tenía que determinar si merecía la pena y que suponía, por tanto, el principal escollo a la hora de convencer a los propietarios de las flotas respecto a la posibilidad de instalar un radar a bordo. Finalmente, Espinosa ponía de manifiesto un problema que ya se ha mencionado y es el desarrollo del radar en diversos países sin comunicación entre ellos. Esto suponía que cada casa proveedora utilizaba su propio diseño con sus propios componentes, lo que hacía que cada casa suministrara repuestos cada uno o dos años a aquellas tripulaciones que instalaban sus equipos. Obviamente, cualquier avería fuera de este periodo de reposición, que se produjera además en un lugar del mundo de difícil acceso para esa casa proveedora suponía un problema para el buen funcionamiento del equipo radar instalado.

En lo que se refiere al personal, el mayor problema era la no presencia a bordo de un equipo especializado en la Marina Mercante, como sí sucedía en la Marina de Guerra. El manejo del radar era razonablemente sencillo, de tal forma que, si todo funcionaba de manera correcta, la tripulación de un barco mercante podía familiarizarse con dicho manejo sin grandes dificultades e, incluso, sentirse más seguros gracias a la incorporación de esta tecnología. El problema aparecía cuando se producían fallos. En los barcos de la Marina de Guerra existía personal especializado a bordo capaz de realizar las reparaciones pertinentes. Sin embargo, en la Marina Mercante eran necesarios cursos de formación para que algunos miembros de la tripulación, generalmente los radiotelegrafistas, adquirieran los conocimientos necesarios para realizar dichas reparaciones. Estos cursos de formación generalmente los proporcionaba la empresa suministradora de los equipos, por lo que no suponían un coste adicional a la instalación del radar, pero en algunos casos suponían un nivel de especialización tan elevado, dada la complejidad de los equipos de la época, que, en muchas ocasiones, creaba cierto agobio en el personal de radiotelegrafía debido a esta nueva responsabilidad, lo que producía un cierto rechazo a la instalación de estos equipos en su barco. Por otro lado, también era necesaria formación especializada para interpretar los datos presentados en la pantalla. En este caso, la responsabilidad recaía, obviamente, en el personal de puente, por lo que se añadió el capítulo de radar en la asignatura de Navegación que se estudiaba en las Escuelas Náuticas, demandándose un esfuerzo de reciclaje por parte del personal que en su momento no había recibido esa formación.

En lo que se refiere al empleo, dada la variedad de soluciones radar que existían, era fundamental que el propietario del buque tuviera claras sus necesidades para poder elegir el proveedor adecuado y que este pudiera, a su vez, proporcionarle aquel equipo que fuera más adecuado para cubrir sus necesidades. Espinosa aconseja priorizar sobre todo la facilidad de manejo, por encima incluso de la perfección de funcionamiento. La facilidad de manejo, incluyendo una gran variedad de mandos que le permitieran al operador decidir en todo momento 
lo que quería hacer con el radar, facilitaba la adaptación de los equipos a los requisitos de cada barco en concreto, disminuyendo los inconvenientes de esta especialización antes mencionada. Por otro lado, el funcionamiento del radar se podía mejorar incluyendo elementos reflectores en puntos y lugares importantes de tierra, así como en los propios barcos, de tal manera que estos pudieran izar un espejo reflector en caso de niebla para facilitar la labor de detección por parte de otros barcos, en estas condiciones climatológicas adversas.

En cuanto a las mejoras de futuro, Espinosa propone disminuir el tamaño de los equipos, fundamentalmente de las antenas, para lo cual una de las opciones más viables sería la utilización de ondas milimétricas ${ }^{35}$. Pero fundamentalmente aboga por la supresión de los intereses comerciales y nacionales que permitieran mejorar una tecnología que se había desarrollado de forma apresurada y fragmentada geográficamente por las necesidades del conflicto bélico. En un escenario posbélico, según Espinosa, era necesario llegar a la normalización y al intercambio de experiencias que permitiera resolver todos los problemas mencionados anteriormente, pero sobre todo fabricar de modo barato y seguro.

Con todos estos condicionantes, en este congreso se presentó un diseño modular propuesto por el INE, que era claramente una propuesta en la línea de lo establecido por su director en la conferencia antes reseñada. Esta era la mayor aportación del radar del INE, un diseño modular muy avanzado para la época que, además, recogía algunas otras aportaciones en cada módulo individual. Para la realización de este diseño modular, que se había iniciado en 1952, se contrató un equipo de ingenieros alemanes. Hay que tener en cuenta que en la época de la llegada de estos ingenieros Alemania todavía tenía prohibido cualquier tipo de investigación y desarrollo relacionado con el radar, por lo que el trabajo en dicha tecnología en España era una buena alternativa para ellos. De todos los ingenieros inicialmente contratados solo vieron el fruto de su trabajo realizado Erich Keller y Richard Schaeffer, de los de la primera oleada de contrataciones, y Hans-Karl Fuchs, Fritz Wächter y Erich Meyer de los colaboradores que se unieron con posterioridad ${ }^{36}$. El resto había regresado ya a su país para la época de la finalización del prototipo o se había dedicado a otras tareas dentro del grupo de microondas del INE, algunas de ellas aprovechables para los equipos radar de la época ${ }^{37}$. Hasta el momento no se conocen datos bibliográficos de los ingenieros alemanes que trabajaron en el radar en España, que constituye un ejemplo más de la colaboración de los laboratorios españoles con técnicos alemanes en los años 40 y 50 que ya existían en los ámbitos nuclear y de construcción de submarinos ${ }^{38}$.

\footnotetext{
${ }^{35}$ De nuevo una tecnología que no se implantaría completamente hasta finales de la década de 1990.

${ }^{36}$ López García, Santiago, El saber tecnológico... op. cit.

${ }^{37}$ Aquí es interesante reseñar el trabajo de W. Ruppel en el desarrollo de procedimientos de medida de microondas que se utilizarían para el diseño y fabricación de muchos equipos que se incluyeron en los prototipos de radar.

${ }^{38}$ Presas i Puig, Albert, "La correspondencia entre José M. Otero Navascués y Karl Wirtz: un episodio de las relaciones internacionales de la Junta de Energía Nuclear", en Arbor, 168 (2000), pp. 527-601; Presas i Puig,
} 
Las necesidades de la época determinaron que la aplicación principal de estos equipos fuera la navegación marítima, aunque posteriormente se utilizaron para la navegación aérea como ya se ha comentado. El equipo capitaneado por estos ingenieros alemanes estaba compuesto además por varios ingenieros españoles, entre los que se pueden citar los nombres de Rafael Domínguez, Felipe Jiménez, Juan Díaz, María de las Nieves Alfonso, Máximo Hernánz, Antonio de la Fuente, Manuel Navajas, Fructuoso Camps y Joaquín de las Doblas ${ }^{39}$. La tarea principal del equipo fue suministrar a la industria española la documentación necesaria para la fabricación de aparatos de radar utilizando elementos de construcción normalizados y de número reducido. La idea era diseñar diferentes tipos de aparatos, según las necesidades, utilizando siempre las mismas piezas estándar, "en cierto modo como en un «mecano», variando de uno a otro la interconexión entre elementos, la construcción mecánica o el dimensionado, de acuerdo con las exigencias particulares"40. Además, para la construcción de los primeros prototipos se dieron normas basadas en el estado del desarrollo de la técnica radar en España. Por otro lado, junto con la unificación y la máxima simplicidad en los componentes y elementos siguiendo las directrices expresadas con posterioridad por el director del INE en la conferencia de Alemania, se introdujeron innovaciones y perfeccionamientos, tanto en la técnica de circuitos como en la parte mecánica, como por ejemplo, un nuevo sistema de mecanismo de arrastre, controlado electrónicamente, para el movimiento de la antena.

La diversidad de tipos de radar que existían en aquella época llevaba aparejado el fraccionamiento de la investigación y la industria de un país que, en el caso de España, llevaba un considerable retraso tecnológico con respecto a otros países. Por este motivo se elaboraron aparatos de exploración panorámica, buscando para sus elementos la mayor flexibilidad de adaptación a los más variados usos y potencias, pero limitando en lo posible el número de tipos indispensables y ampliando la zona de aprovechamiento de cada tipo, de tal forma que los primeros tipos desarrollados, se dedicaron al uso civil, procediéndose posteriormente a la ejecución de otros tipos de aplicación militar, basándose en los resultados obtenidos en los anteriores. López García señala que el INE recibía una financiación anual de 6 millones de pesetas por parte del Ejército, de ahí la inmediata aplicación militar de los equipos desarrollados ${ }^{41}$. Sin embargo, este trabajo se ha centrado en las aplicaciones civiles, dejando las aplicaciones militares para una futura investigación.

La idea de la utilización de elementos estándar, tanto para la racionalización de la fabricación y rapidez del desarrollo, como para la limitación del número de elementos necesarios para construir los diferentes tipos de equipos y para la sustitución de partes averiadas, llevada a la práctica en la construcción de los equipos radar, era muy típica en la industria española

\footnotetext{
Albert, "Spain in 1952 as seen by a German warship builder", en MPIGW Preprint, 300 (2005).

${ }^{39}$ Manual de equipos de radar de banda X. Instituto Nacional de Electrónica, 1955 (documento inédito).

${ }^{40}$ Ibídem.

${ }^{41}$ López García, Santiago, El saber tecnológico... op. cit.
} 
de la época, dados los condicionantes de la misma ${ }^{42}$. Se trata de una época donde la autarquía había dado paso a la sustitución de importaciones y el radar formaba parte de esta tendencia de la ciencia y la tecnología del régimen franquista. El objetivo era ser capaz de satisfacer la demanda futura del país de aparatos e instalaciones de radar de las más variadas clases. El ánimo fundamental era acortar el plazo que va desde el planteamiento específico de cada problema hasta la puesta a punto y comprobación del prototipo correspondiente, "sin incertidumbre en el resultado que se pretende" ${ }^{43}$. Además de razones industriales para el desarrollo de un radar en España, también existían razones de tipo técnico. Hay que tener en cuenta que en los prototipos conocidos en la época, con los medios de los que disponían, ya habían alcanzado los límites de las posibilidades físicas respecto a la localización de obstáculos o blancos. Por ese motivo, el mayor interés en cuanto al desarrollo de nuevos prototipos, era aumentar el rendimiento del radar.

Para entender las soluciones adoptadas por el grupo de microondas es preciso describir brevemente los factores de los que depende ese rendimiento. Los parámetros relevantes son el alcance, las resoluciones radial y azimutal ${ }^{44}$, y la precisión en la medida de la posición del blanco. El alcance, a su vez, es función de la potencia emitida, de la sensibilidad del receptor y de la ganancia de la antena. Esta ganancia depende de la forma y dimensiones de la antena, que a su vez determinan la resolución azimutal. En general, dicha resolución será tanto mayor cuanto mayores sean estas dimensiones que, evidentemente, están limitadas por las posibilidades mecánicas y las condiciones de instalación. La potencia del emisor tiene una cota superior que viene dada por los tubos disponibles y por los elementos que lo unen a la antena. En lo que se refiere a la sensibilidad del receptor, o factor de ruido, depende del ruido propio de los elementos y de los circuitos utilizados en las primeras etapas. Los primeros venían limitados por la disponibilidad del mercado en la época, pero en los circuitos se realizaron unas mejoras que se comentarán posteriormente. Finalmente, en lo que se refiere a la resolución radial, esta es proporcional a la anchura del impulso y al poder de resolución del tubo indicador. La anchura del impulso no se podía disminuir indefinidamente, porque implicaba un aumento de la anchura de banda del receptor, lo que producía un incremento proporcional del espectro de ruido transmitido, por lo que las mejoras se tenían que introducir en la resolución del tubo.

Con todo lo anterior, el objetivo del equipo del INE fue construir un equipo de radar comenzando por un acertado funcionamiento del mismo en bloques y elementos de construcción eléctrica y mecánica sencilla y que, por sus innovaciones en circuitos, conexionado, seguridad

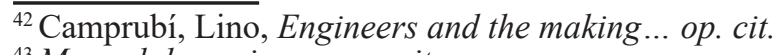

${ }^{43}$ Manual de equipos... op. cit.

${ }^{44}$ La resolución radial es la capacidad de un sistema radar para distinguir entre dos o más objetivos situados en el mismo rumbo, pero a diferente distancia, mientras que la resolución azimutal es la capacidad del sistema de distinguir dos objetivos a la misma distancia, pero situados en diferente rumbo.
} 
en la puesta a punto y simplicidad de uso, fuesen adaptables al mayor número posible de equipos, tratando de establecer una base firme para la creación de una industria española del radar. El trabajo se dividió entre diferentes miembros del laboratorio, estableciéndose unos mecanismos de colaboración y de coordinación entre ellos. Por ejemplo, dado que se trataba de un radar monoestático, es decir, cuya antena se utilizaba tanto para transmisión como para recepción, en el desarrollo de la misma tenían que intervenir miembros del equipo de emisión-modulación, de transmisión de la señal de radiofrecuencia y de recepción. Todos los perfeccionamientos e innovaciones fueron patentados a favor del Patronato Juan de la Cierva, muchos de ellos relacionados con el tubo de rayos catódicos ${ }^{45}$.

Una muestra de que la tecnología utilizada en España era homologable a lo que se estaba haciendo en otros países se encuentra en el hecho de que cuando el prototipo desarrollado fue presentado en el congreso de Bremen de 1954, los derechos de fabricación y venta para el territorio alemán fueron inmediatamente adquiridos por la empresa alemana Einsenwerke Kaiserlautern. Alemania solo podía construir radares comprando licencias extranjeras, por lo que se da la situación curiosa de tener que importar una tecnología desarrollada, en gran medida, por algunos de sus ingenieros que tras la II Guerra Mundial, encontraron acomodo bajo el régimen franquista como se ha comentado antes. Sin embargo, el proyecto de fabricación y venta de este prototipo no se llevó a cabo, debido a que cuando se iba a iniciar su producción en serie, Estados Unidos empezó a apoyar con su armamento de defensa a Alemania, copando todo el mercado relativo a equipamiento electrónico ${ }^{46}$. Finalmente, se debe mencionar que el trabajo del equipo de radar del INE recibió el Premio Francisco Franco de Investigación Técnica para trabajos desarrollados en equipo en el año 1955. Este fue el primer año que se otorgaron los premios destinados a la investigación técnica, incluyendo dos categorías: individual y por equipos, ya que hasta ese momento las categorías existentes eran la de Ciencias y la de Letras.

\footnotetext{
${ }^{45}$ Hasta diez patentes se recogen para equipos radar en la época de desarrollo de estos prototipos. Son las siguientes: Patente ES0206809 A1 del 16 de octubre de 1953: "Un dispositivo para un aparato de radar"; Patente ES0215395 A1 del 1 de julio de 1954: "Un dispositivo de ajuste de la anchura de banda para receptor de radar"; Patente ES0215393 A1 del 1 de julio de 1954: "Nuevo dispositivo para el mando de antenas de radar"; Patente ES0224376 A1 del 16 de enero de 1956: "Dispositivo para aumentar la definición de imágenes radar por diferenciación"; Patente ES0224375 A1 del 16 de enero de 1956: "Dispositivo y procedimiento para aumentar la sensibilidad de los aparatos de radar en la indicación de blancos lejanos"; Patente ES0224753 A1 del 1 de febrero de 1956: "Un sistema de mando de la desviación de un haz catódico en una lupa de radar"; Patente ES0224755 A1 del 1 de febrero de 1956: "Un procedimiento de control de la ganancia de equipos de radar y dispositivo para realizarlo"; Patente ES0224754 A1 del 16 de febrero de 1956: "Un dispositivo de seguridad para equipos radar"; Patente ES0227659 A1 del 16 de mayo de 1956: "Dispositivo de mando para la antena de un radar dotado de lupa electrónica"; Patente ES0232818 A1 del 16 de mayo de 1957: "Dispositivo para obtener en un haz de rayos catódicos desviaciones proporcionales a la posición angular del eje de una antena de radar dotada de movimiento de exploración panorámico o sectoral".

${ }^{46}$ Sobre el papel de Estados Unidos bloqueando acuerdos se pueden consultar: Presas i Puig, Albert, "Science on the periphery: the Spanish reception of nuclear energy: an attempt at modernity?", en Minerva, 43 (2005), pp. 197 218; Camprubí, Lino y Simon Turchetti, "From the ground up: uranium surveillance and atomic energy in western Europe", en Roberts, Peter y Simone Turchetti (eds.), The surveillance imperative. Geophysics in the cold war and beyond, Basingtok, Palgrave MacMillan, 2014, pp. 23-44.
} 
2. Especificaciones técnicas

Sin querer entrar en detalles técnicos, es interesante, en la tarea de recuperar estos prototipos, comentar brevemente sus características y sus principales aportaciones a la tecnología de la época, recogidas en las patentes mencionadas. Obviamente, las características generales de este radar venían fijadas por las necesidades particulares de la navegación marítima. Con esta idea, la longitud de onda de trabajo elegida fue de $3 \mathrm{~cm}$, equivalente a una frecuencia de $10 \mathrm{GHz}$, correspondiente a la banda X que era la utilizada generalmente para los radares de la época ${ }^{47}$. El objetivo era conseguir un compromiso entre la obtención de la máxima directividad de la antena, con unas dimensiones tolerables y la necesidad de tener que trabajar en condiciones atmosféricas y meteorológicas arbitrarias. Hay que tener en cuenta que por debajo de los $3 \mathrm{~cm}$, aumenta la absorción en caso de niebla, lluvia o granizo y disminuye considerablemente la potencia que se puede transmitir. Estas limitaciones no son importantes por encima de los $3 \mathrm{~cm}$, pero para llegar a una definición en azimut razonable, el tamaño de las antenas sobrepasaba la disponibilidad material de la época.

Por otro lado, el alcance máximo dependía de la velocidad de entrada del barco y del tiempo necesario para la preparación de las maniobras una vez recibidas las órdenes correspondientes. A la hora del diseño se consideró una velocidad normal de entrada de 10 nudos $(18 \mathrm{~km} / \mathrm{h})$ y un tiempo de media hora de preparación, por lo que el alcance máximo quedaba limitado a 10 $\mathrm{km}$. En cuanto a la resolución radial, se fijó de tal manera que en la zona de máximo interés, la entrada propiamente dicha del puerto, que queda dentro de un radio de $1 \mathrm{~km}$, dos objetos cuya distancia fuera igual o superior a 10 metros quedaran perfectamente separados. Esta resolución radial quedaba fijada por la anchura del impulso y por el tamaño de la mancha luminosa en la pantalla ${ }^{48}$. Sin embargo, para las distancias más alejadas, la mancha luminosa en la pantalla limitaba esta resolución para distancias mayores, ya que al ser de diámetro finito cubría una extensión real determinada que era mayor cuanto mayor fuera el alcance. Los equipos instalados llevaban un tubo con pantalla de $36 \mathrm{~cm}$ de diámetro, consiguiéndose un diámetro de la mancha luminosa del orden de $0,5 \mathrm{~mm}^{49}$.

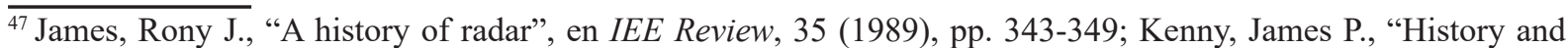
development of radar", en Students' Quarterly Journal, 30 (1960), pp. 83-91; Ottanelli, Andrea “Il radar...” op. cit. ${ }^{48}$ Para las distancias de $1 \mathrm{~km}$, está limitación venía dada exclusivamente por la duración del impulso que, para discernir distancias de 10 metros, necesitaba ser de aproximadamente 70 nseg.

${ }^{49}$ Esto significa que para el alcance máximo de $10 \mathrm{~km}$, esta distancia estaba representada en el tubo por 180 $\mathrm{mm}$ y, por tanto, un milímetro en la pantalla equivalía a una longitud real de $55 \mathrm{~m}$, que hacía que la mancha luminosa cubriera un espacio equivalente a, aproximadamente, $28 \mathrm{~m}$. Asumiendo que el ojo humano aprecia desplazamientos de la mitad de este diámetro, estamos hablando de una discriminación de blancos de $14 \mathrm{~m}$ a la distancia del alcance máximo de $10 \mathrm{~km}$.
} 
En lo que se refiere a la resolución azimutal, esta quedaba definida por la anchura horizontal del haz de radiación, limitada a $0,6^{\circ}$ para conseguir la discriminación antes mencionada de $10 \mathrm{~m}$, no siendo importante la anchura vertical, ya que la antena no tenía ningún movimiento vertical al estar el radar destinado a la detección de barcos en superficie. La frecuencia de repetición se eligió teniendo en cuenta la necesidad de que en cada obstáculo incidieran un número suficiente de impulsos y la disipación admisible en las válvulas empleadas ${ }^{50}$. La potencia de transmisión debía ser suficiente para la detección de boyas y embarcaciones pequeñas a la distancia deseada, y se obtenían con el magnetrón $725 \mathrm{~A}$, ampliamente utilizado por los equipos radar desarrollados por los aliados en la II Guerra Mundial ${ }^{51}$.

El tipo de indicación era el clásico de la época por pantalla indicadora o PPI (Plan Position Indicator), indicando los ecos como puntos luminosos situados en la posición que les correspondería en el mapa. Se podían elegir cuatro márgenes de distancia: de 0 a 1 , de 0 a 2,5, de 0 a 5 o de 0 a $10 \mathrm{~km}$, representándose en la pantalla círculos de distancia, con separaciones entre uno y el siguiente, que, según los márgenes de distancia, podían ser de 0,2, 0,5, 1 o $2 \mathrm{~km}$. En este aspecto es donde más novedades se introdujeron por el equipo del INE con respecto al estado de la tecnología de la época en otros países, como se ha mostrado en la sección anterior con la gran cantidad de patentes dedicadas a la indicación y a la denominada lupa del radar. Por tanto, al igual que en el caso de la transmisión se seguían los principios que los ingenieros aliados habían seguido en la II Guerra Mundial, introduciendo ciertas mejoras correspondientes a las patentes mencionadas en la sección anterior.

El equipo, que se designó como R X 40/M11, estaba formado por tres unidades enlazadas entre sí. En primer lugar, estaba la unidad de transmisión que generaba el impulso de alta potencia, los circuitos de conmutación electrónica entre transmisión y recepción, la conversión de radiofrecuencia a frecuencia intermedia y el preamplificador de frecuencia intermedia. En segundo lugar, la unidad de indicación, con el tubo indicador y los circuitos necesarios para obtener la imagen: una cadena de amplificación y detección de la señal, el sistema de barrido del haz de los rayos catódicos y los elementos de calibración en distancia, de mando y de alimentación. Finalmente, la unidad de antena, formada por la antena propiamente dicha, una junta rotatoria que unía la antena con la guía de ondas que, a su vez, conectaba la unidad de antena con la unidad de transmisión, el mecanismo de arrastre de la misma y la unidad de transmisión de los datos de posición instantánea de la antena. La Figura 1 muestra el diagrama de bloques del equipo.

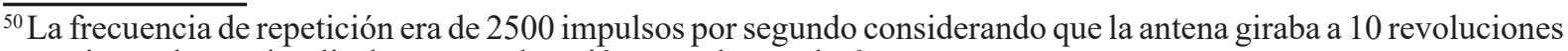
por minuto, lo que implicaba una exploración completa cada 6 seg.

${ }^{51} \mathrm{La}$ potencia de transmisión de estos equipos se fijó en $40 \mathrm{~kW}$.
} 
Figura 1: Diagrama de bloques de los radares de banda $\mathrm{X}$ desarrollados por el INE.

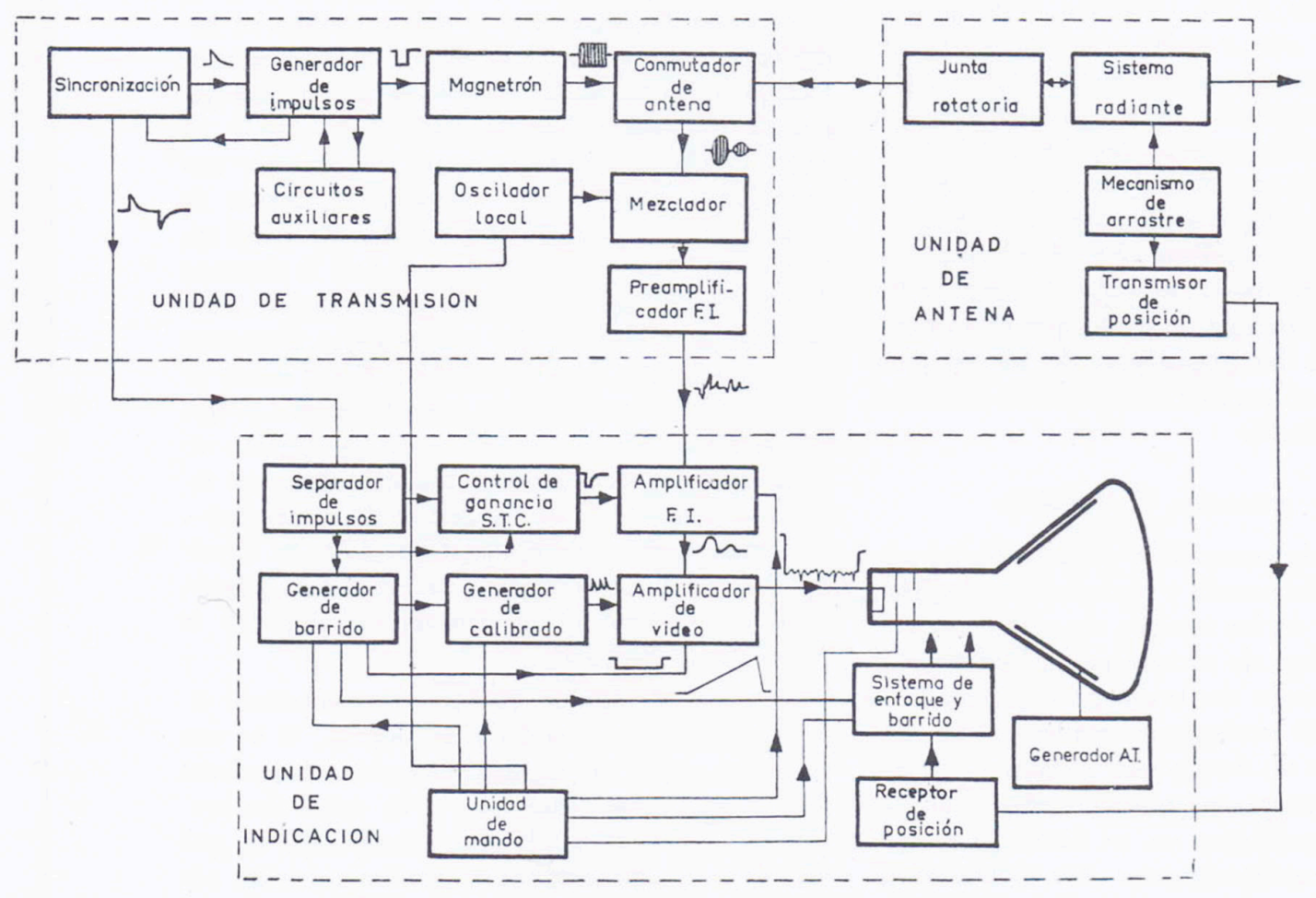

Fuente: Manual de equipos... op. cit.

Uno de estos equipos se conserva en los pasillos del Instituto Leonardo Torres Quevedo del CSIC. Sin embargo, no se ha realizado una labor exhaustiva de estudio de ese prototipo conservado ni se ha recuperado su historia, circunstancia que es el objetivo principal de este trabajo. Las Figuras 2 y 3 muestran varias imágenes de este prototipo conservado. 
Figura 2: Vista frontal del prototipo conservado en el Instituto Leonardo Torres Quevedo.

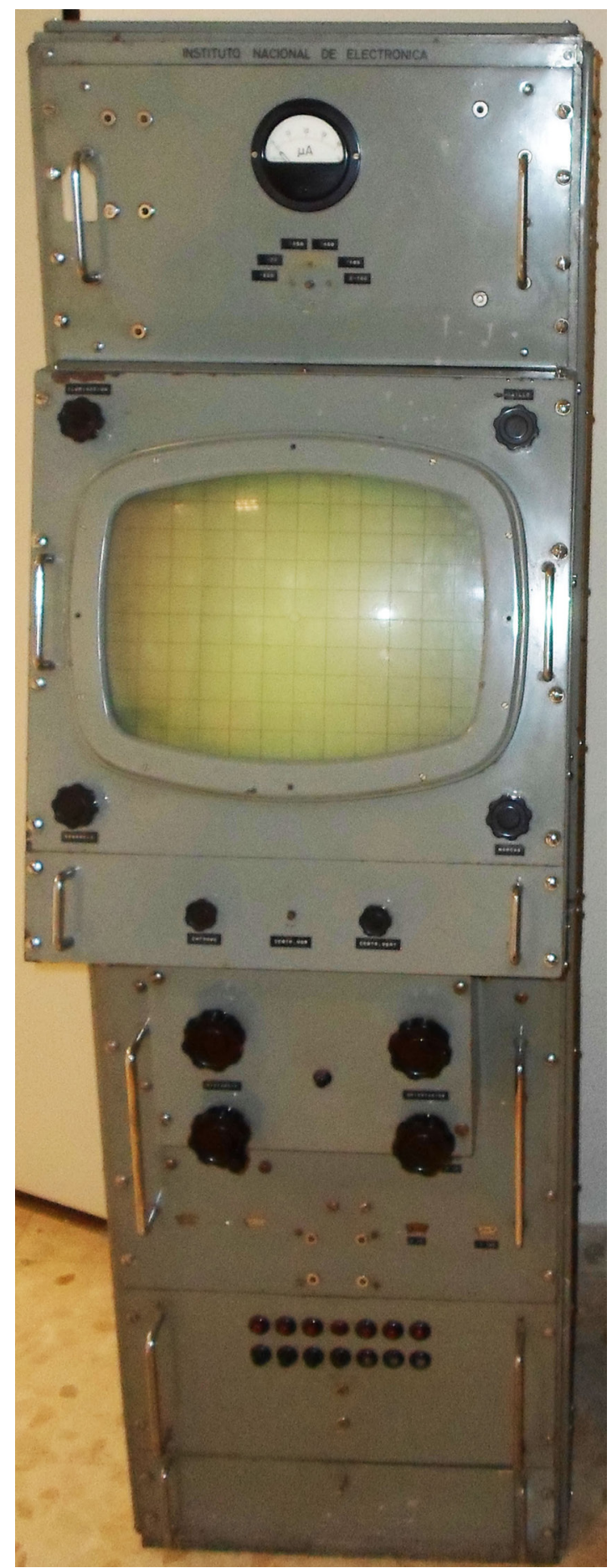

Fuente: Fotografía del autor. 
Figura 3: Vista interior del prototipo conservado en el Instituto Leonardo Torres Quevedo.

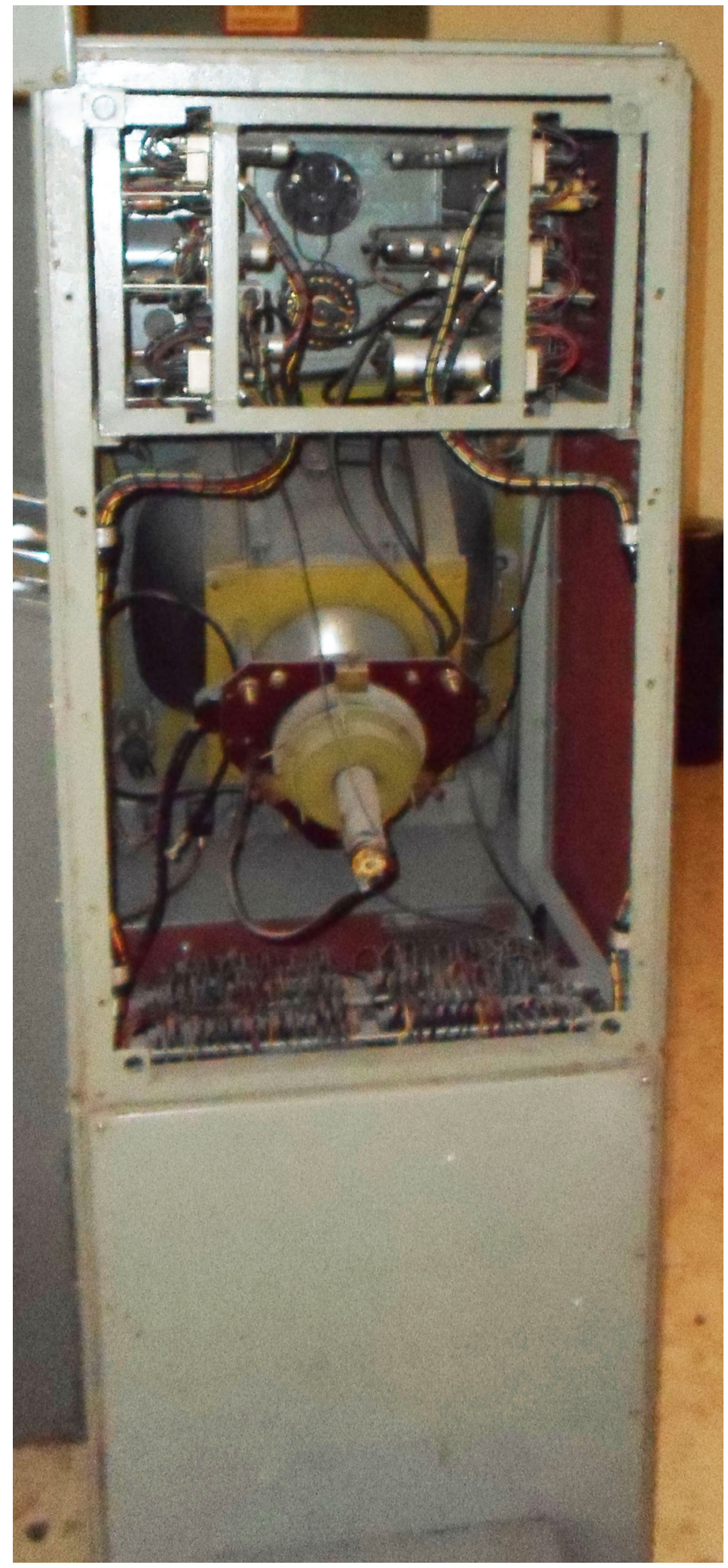

Fuente: Fotografía del autor. 


\section{Pruebas realizadas}

Es interesante documentar las pruebas que se realizaron en los aparatos de radar desarrollados con el fin de comprobar su correcto funcionamiento en condiciones de utilización ${ }^{52}$. Se realizaron dos tipos de pruebas, primero en tierra, en Madrid, en septiembre de 1953, y luego ya en condiciones de navegación en El Ferrol, en diciembre del mismo año. La idea de realizar estos dos tipos de pruebas obedecía no solo a la mayor comodidad de realizar primero pruebas en Madrid, sino también en someter al radar a condiciones climatológicas diferentes.

En las pruebas de Madrid se realizó, en primer lugar, la puesta a punto de todos los elementos de los equipos, subsanando los fallos que aparecen en toda primera prueba y tratando también de corregir los defectos propios de un funcionamiento prolongado. En segundo lugar, se buscó el perfeccionamiento de todo el equipo funcionando en conjunto con el fin de lograr un óptimo rendimiento. Una vez conseguido se hicieron fotos de la pantalla PPI, obtenidas con un emisor de potencia de cresta de $40 \mathrm{~kW}$. La Figura 4 muestra un ejemplo de estas capturas de pantalla donde se ven las primeras estribaciones de la Sierra de Gredos a una distancia de entre 70 y $80 \mathrm{~km}^{53}$. La reproducción de las figuras no es la mejor dadas las condiciones técnicas de la época, pero se considera interesante su reproducción para ilustrar las pruebas realizadas.

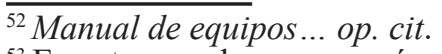

${ }^{53}$ En estas pruebas se superó ampliamente el alcance máximo indicado anteriormente para detectar barcos en su entrada a puerto debido a que esa limitación correspondía a blancos en movimiento y venía dada por la velocidad de estos blancos y no por la potencia de emisión del radar. En las pruebas se trataba de mostrar la imagen obtenida para diferentes alcances sin incluir, para los alcances mayores, la detección de blancos en movimiento.
} 
Figura 4: Vista desde la Ciudad Universitaria. Alcance $50 \mathrm{~km}$. Vista de la Sierra de Gredos.

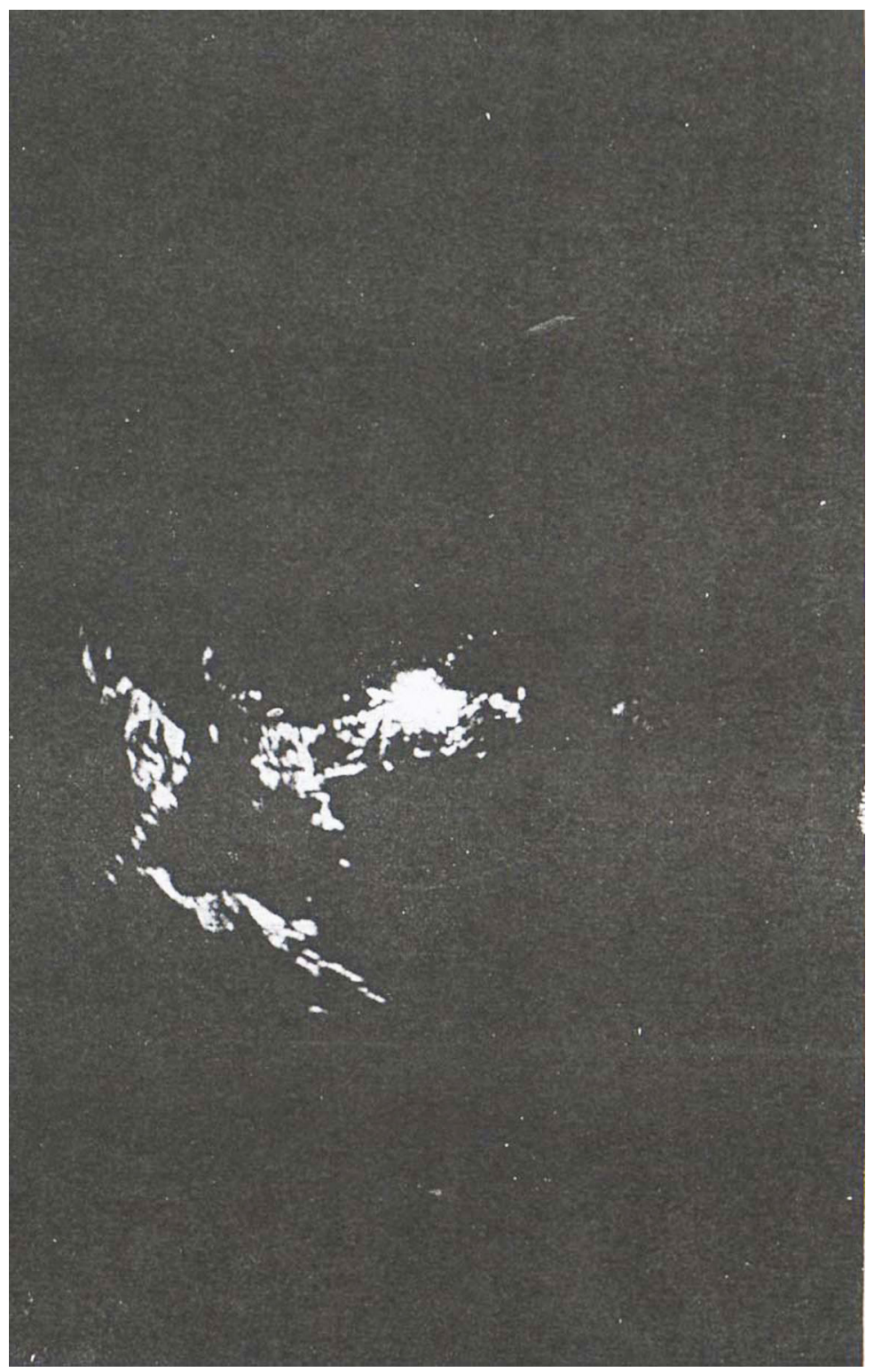

Fuente: Manual de equipos de radar de banda X. 1955

En lo que se refiere a las pruebas de El Ferrol, se realizaron, obviamente, para estudiar el funcionamiento del equipo en clima marítimo, además de para comprobar la definición en distancia y azimut o rumbo, y la posibilidad de persecución continua de un blanco móvil con el movimiento de la antena, y la presentación de este blanco en la lupa. La antena se instaló en una torreta (Figura 5), con ventanas transparentes a la radiación electromagnética, para protegerla de los excesos climáticos. La Figura 6 muestra un ejemplo de captura en los alrededores del equipo en la que se ve un blanco móvil encuadrado en la zona de observación de la lupa electrónica, correspondiendo el trapecio circular más iluminado a dicha zona. Se observa en esa figura la 
marca móvil y la indicación del movimiento de la antena, que permitían medir la distancia y el azimut.

Figura 5: Instalación de la antena en las pruebas de El Ferrol.

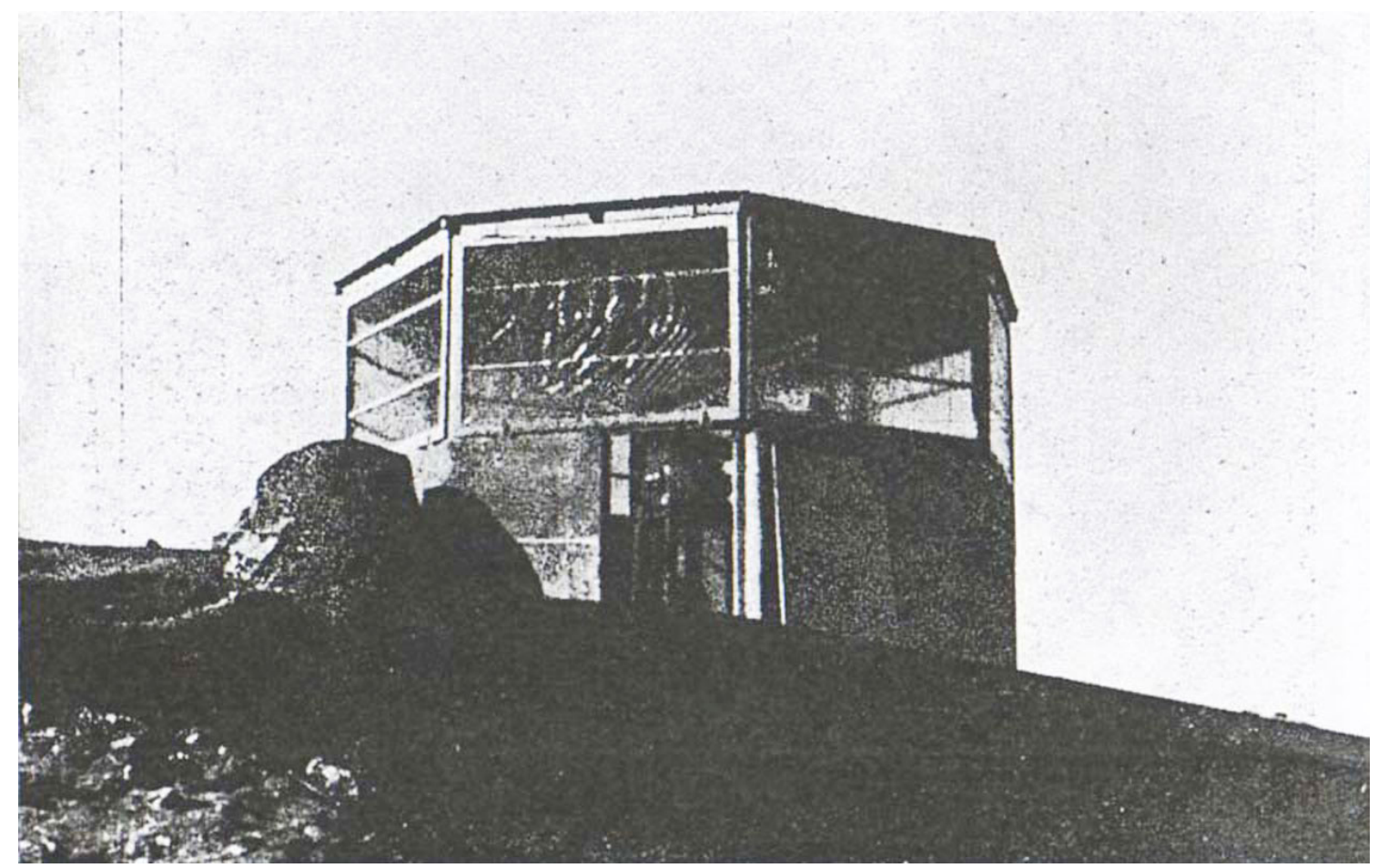

Fuente: Manual de equipos... op. cit. 
Figura 6. Zona de observación de la lupa. Alcance $20 \mathrm{~km}$.

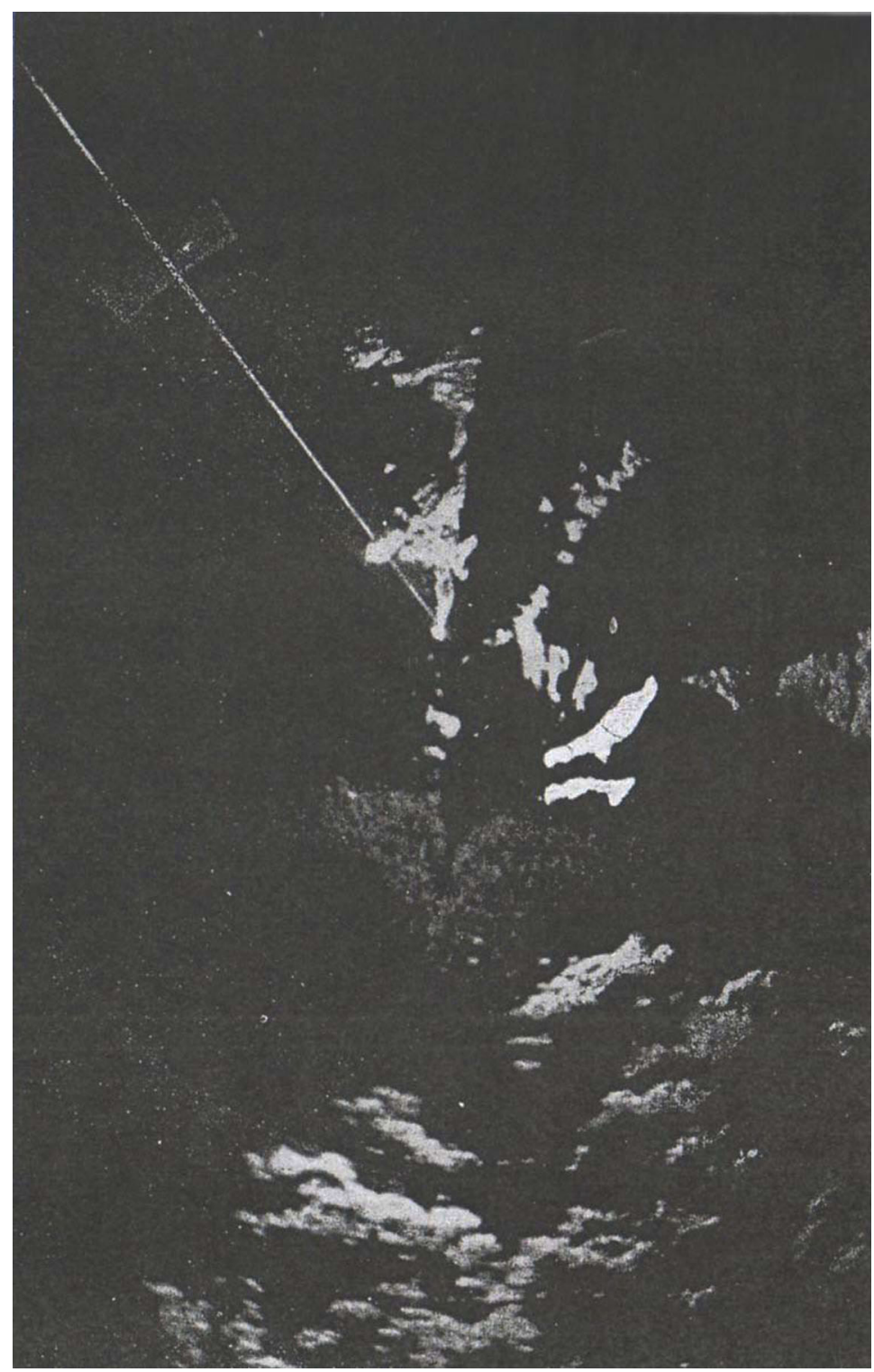

Fuente: Manual de equipos... op. cit.

Una vez realizados estos prototipos y probados correctamente se trataron de instalar en los puertos más importantes del territorio español. Además, otro de los objetivos era equipar a las embarcaciones españolas con este tipo de equipo, ya que la presencia de radares tanto en los puertos como en las embarcaciones mejoraba la seguridad en la navegación marítima, la mayor parte de las flotas de otros países ya estaban equipados con algún tipo de ayuda a la navegación y, técnicamente, eran problemas muy similares. Sin embargo, el mayor problema a la hora de la instalación de este tipo de radares en embarcaciones pequeñas era su elevado precio para algunas de las compañías navieras, pese al esfuerzo realizado para disminuir el coste y a la 
utilización de la fabricación en serie. Así, uno de los trabajos del INE fue la realización de un radar de baja potencia y relativamente bajo coste que pudiera contribuir a la seguridad de los barcos de pequeño tonelaje. Este ahorro, sin embargo, se encontraba con el problema de que la conservación del radar en condiciones de servicio, así como la interpretación de las imágenes proporcionadas, recaía en personal especializado que, la mayoría de las veces, las flotas de barcos no se podían permitir. De esta manera, la mayoría de los barcos destinados a la navegación de cabotaje o a la pesca de cercanías no hacían uso de los sistemas radar al entrar y salir de los puertos ni al circular por ellos. Estas reticencias hicieron que se retrasara la instalación generalizada de radares en los puertos españoles, de tal forma que, cuando esta se realizó, la compra de tecnología proveniente de los Estados Unidos derivada de los pactos firmados de 1953, tuvo como consecuencia que muchos de los radares instalados en los puertos españoles provinieran de aquel país, impidiendo un desarrollo más intensivo de una tecnología en la que se había logrado un acercamiento tecnológico al nivel de lo que se estaba realizando en otros países durante esos años. La adquisición de radares de origen estadounidense fue paulatina hasta mediados de la década de 1960, por lo que durante ese tiempo los proyectos de desarrollo de tecnología radar de fabricación nacional continuaron, pero se vieron fuertemente condicionados por la presencia de tecnología norteamericana que se utilizaba, fundamentalmente, cuando los equipos de fabricación nacional mostraban sus limitaciones (en puertos grandes, por ejemplo) lo que disminuyó, probablemente, las posibilidades de desarrollo de la tecnología radar en España.

\section{Aplicación a la navegación aérea}

Uno de los principios de diseño de los radares del INE era su modularidad, con el fin de poder utilizarse en otras aplicaciones. Con esta idea, a finales del año 1957 se empezaron a realizar pruebas en el aeropuerto de Barajas con el fin de realizar prototipos que fueran aplicables al tráfico aeronáutico. La idea era someter a los equipos a condiciones de funcionamiento especialmente crítico para comprobar su funcionamiento y además contar con el asesoramiento de los técnicos aeronáuticos y de los posibles usuarios de estos equipos para realizar un desarrollo acorde a las necesidades de los servicios aéreos. Se trataba de desarrollar equipos multifuncionales, ya que la complejidad y el precio de este tipo de equipos aconsejaba intentar un aprovechamiento de los mismos lo más alto posible. Entre 1950 y 1957, la Organización Internacional de la Aviación Civil había ido normalizando tanto los requisitos necesarios para el radar primario (situado en la 
torre), como para el radar secundario (situado en el avión) ${ }^{54}$. Sin embargo, el INE consideraba que esos requisitos solo se podían cumplir en "naciones de técnica muy avanzada", mientras que los países menos desarrollados como España debían producir otros equipos radar que, sin ajustarse totalmente a las prescripciones de los organismos internacionales, proporcionasen a la navegación aérea una ayuda realmente eficaz ${ }^{55}$. De nuevo, se trataba de la preocupación por la estandarización tan característica de la labor de los ingenieros en la España franquista. La idea era superar las condiciones meteorológicas mínimas que el reglamento nacional estipulaba para que cada aeropuerto quedara cerrado al tráfico, de tal forma que un estudio particular del área de influencia de un aeropuerto, incluyendo las características orográficas y meteorológicas propias de cada región, permitiera aconsejar un tipo de radar multifuncional que estuviera dentro de las posibilidades de la industria electrónica nacional, con el objetivo de que, aunque no se cumpliera la normativa internacional, sí, al menos, aumentar la explotación de cada aeropuerto en cuanto a su tráfico, con el consiguiente beneficio económico. La Figura 7 muestra algunas de las pruebas realizadas.

Figura 7: Imagen de las pruebas a $70 \mathrm{~km}$ del radar.

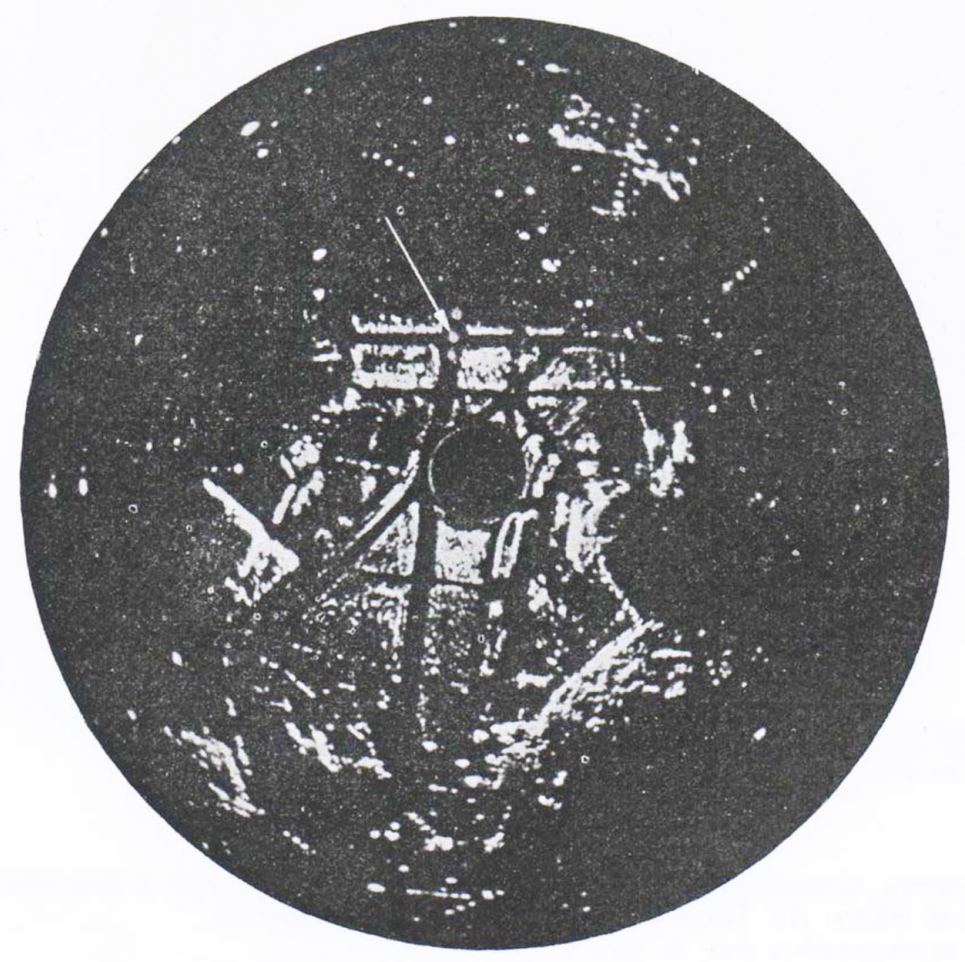

Fuente: Revista del INE, 2 (1958), pp. 95-97.

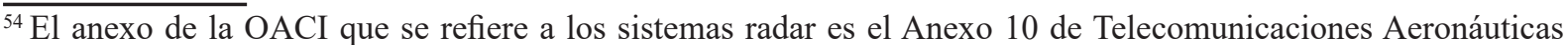
Volumen IV (Radares de Vigilancia y Sistemas para Evitar Colisiones).

${ }^{55}$ Noticia aparecida en Revista del INE, 2 (1958), pp. 95-97.
} 


\section{Conclusiones}

En este artículo se ha tratado de recuperar la historia de la introducción de la tecnología radar en España. Se ha centrado el trabajo en el radar de navegación marítima por ser la primera aplicación de la que se recoge documentación, aunque se ha comentado la aplicación posterior a la navegación aérea tras la adaptación de los prototipos desarrollados. Se ha mostrado cómo el radar en España se desarrolla a partir de la contratación de una serie de ingenieros alemanes que, con posterioridad a la II Guerra Mundial abandonaron su país, buscando refugio, tras haber colaborado en los estudios de radar del régimen nazi. Estos científicos fueron contratados para formar escuela y acelerar el proceso de lo que Santiago López García llama el acercamiento tecnológico. Es importante subrayar dos aspectos, la influencia que sobre estos ingenieros tuvieron los avances aliados en materia de radar como grandes triunfadores del conflicto bélico $\mathrm{y}$, el hecho de que el radar fuera uno de los pocos desarrollos tecnológicos españoles en los que se logró el acercamiento tecnológico antes mencionado, es decir, lograr resultados con un nivel similar a lo que se estaba haciendo en otros países en la época. Por ese motivo, se ha considerado oportuno en el trabajo recoger las especificaciones técnicas de los equipos desarrollados para mostrar con más detalle dicho nivel de desarrollo tecnológico.

Este trabajo incorpora a la historiografía de la ciencia y la tecnología industrial en el franquismo una tecnología hasta ahora olvidada dentro de la misma, como es la tecnología de microondas, concretamente el radar. Se ha conseguido recuperar una serie de prototipos olvidados hasta el momento que, pese a que se conservan (sin demasiado cuidado) en alguna de las instituciones de investigación española, nunca se había estudiado su historia. Por ese motivo, se ha abordado dicho estudio, comparando sus especificaciones con el estado de la tecnología en otros países. Teniendo en cuenta que el radar fue uno de los campos de estudio donde la ciencia franquista alcanzó un nivel más destacado en comparación con otros países, la recuperación de esta tecnología adquiere un papel de gran importancia a la hora de recuperar la ciencia de dicho periodo histórico.

El trabajo se ha centrado fundamentalmente en los primeros prototipos desarrollados, describiendo el proceso que llevó a su desarrollo y realizando una descripción de los mismos, lo que constituye una importante aportación ya que permite entender de forma más precisa el desarrollo tecnológico que se alcanzó en materia de radar en el INE a principios de los años 50 , especialmente en los radares dedicados a la navegación marítima. Se han incluido también las pruebas realizadas, que son una muestra más de la capacidad de los equipos desarrollados. Esta capacidad y, sobre todo, su modularidad, una de sus principales aportaciones tecnológicas, 
queda también demostrada por su posibilidad de adaptación a la navegación aérea, razón por la cual se ha incluido dicha aplicación como parte del artículo. Este artículo es pionero en el estudio de la introducción del radar en España y como tal, abre líneas de trabajo futuras como, por ejemplo, el estudio de las circunstancias de trabajo de los ingenieros alemanes en España y del equipo de ingenieros españoles (en los que se incluía la presencia femenina de María de las Nieves Alfonso, cuyo papel sería interesante estudiar) así como la interacción entre ambos equipos. Otro aspecto importante es el desarrollo futuro que tuvieron estos radares y su instalación en los puertos españoles y su convivencia con las importaciones de tecnología estadounidense realizada a partir de los pactos de 1953, circunstancia que se debe estudiar tomando como punto de partida el estudio de los prototipos aquí presentados. 